\title{
This side up
}

\author{
Barry Gibney, DO, and Chadrick E. Denlinger, MD
}

\author{
From the Division of Cardiothoracic Surgery, Department of Surgery, Medical University of South Carolina, \\ Charleston, SC. \\ Disclosures: Authors have nothing to disclose with regard to commercial support. \\ Received for publication Oct 4, 2018; accepted for publication Oct 5, 2018; available ahead of print Nov 7, 2018. \\ Address for reprints: Chadrick E. Denlinger, MD, Division of Cardiothoracic Surgery, Department of Surgery, \\ Medical University of South Carolina, 114 Doughty St, Charleston, SC 29425 (E-mail: denlinge@musc.edu). \\ J Thorac Cardiovasc Surg 2019;157:434 \\ $0022-5223 / \$ 36.00$ \\ Copyright (C) 2018 by The American Association for Thoracic Surgery \\ https://doi.org/10.1016/j.jtcvs.2018.10.011
}

Primary graft dysfunction (PGD) is a common phenomenon that is well-described after lung transplantation and is recognized radiographically by the presence of pulmonary infiltrates and physiologically by diminished oxygenation. The manifestations of PGD are analogous to acute respiratory distress syndrome (ARDS) and in fact, when grading their severity, PGD and ARDS have comparable scoring systems. Although a significant amount of research effort has been devoted to the etiology of both ARDS and PGD, a specific treatment remains elusive. Instead, management for each condition remains supportive. Given the similarity of the 2 conditions, it is entirely reasonable to extrapolate knowledge gained from one condition to the other.

Prone positioning of patients has been effectively used as a strategy to improve the oxygenation of patients with ARDS, with clinical evidence demonstrating improved outcomes. ${ }^{1}$ The early use of prone positioning in patients with ARDS has not been widely adopted because the process is labor-intense and it carries some risk for the inadvertent displacement of the endotracheal tube and other devices. However, randomized, prospective trials have demonstrated a significant reduction in 28-day and 90-day mortality. ${ }^{2}$

The physiological explanation for the efficacy of prone positioning relates to the recruitment of dorsal portions of the patient's lung, which develop atelectasis after prolonged periods in the supine position. Clinicians have observed radiographic redistribution of pulmonary densities after prone positioning, and pulmonary compliance has improved. Collectively, these observations have led to the belief in improved matching of ventilation and perfusion with enhanced alveolar recruitment leads to the improved oxygenation and ultimately survival. A critical detail of this physiology is the reversing of the hospitalized patient from the standard supine position to prone.

In this issue of the Journal, Niikawa and colleagues ${ }^{3}$ interestingly extrapolate the concept of prone positioning of patients with ARDS to prone positioning of ex vivo lungs mean.

\section{References} 368:2159-68.

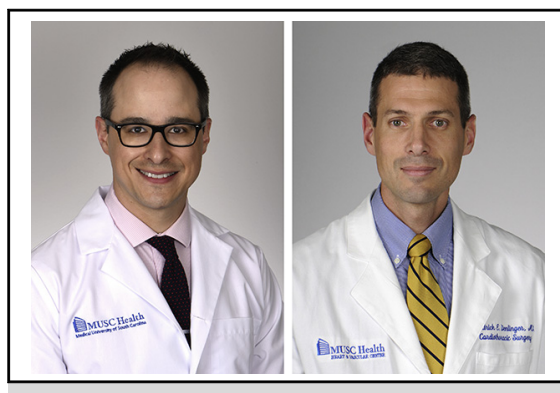

Barry Gibney, DO, and Chadrick E. Denlinger, MD

Central Message

Primary graft dysfunction and ARDS have many physiological similarities. Prone positioning of lungs in each condition appears beneficial, whereas the porcine model raises interesting questions.

See Article page 425 .

using a porcine model. The authors observed improved oxygenation, greater lung compliance, lower wet to dry ratios, and reduced inflammatory cytokine release when the porcine lungs were prone ex vivo compared with supine. Collectively, these findings are consistent with an attenuated ischemia reperfusion injury. These results are very interesting, because the natural position of a quadrupedal pig (prone) is exactly opposite that of a traditional hospitalized patient (supine). Therefore, placing ex vivo porcine lungs in the prone position essentially restores the natural position of these lungs, and this was associated with improved pulmonary function. If this is true, perhaps the best position for human ex vivo lungs is upright. Niikawa and colleagues ${ }^{3}$ have made some interesting observations in their ex vivo lung perfusion model, and further investigations will be necessary to help interpret what they really

1. Guerin C, Gallard S, Lemasson S, Ayzac L, Girard R, Beuret P, et al. Effects of systematic prone positioning in hypoxemic acute respiratory failure: a randomized controlled trial. JAMA. 2004;292:2379-87.

2. Guérin C, Reignier J, Richard JC, Beuret P, Gacouin A, Boulain T, et al. Prone positioning in severe acute respiratory distress syndrome. N Engl J Med. 2013;

3. Niikawa H, Okamoto T, Ayyat KS, Itoda Y, Farver CF, McCurry KR. The protective effect of prone lung position on ischemia-reperfusion injury and lung function in an ex vivo porcine lung model. J Thorac Cardiovasc Surg. 2019;157:425-33. 